\title{
Modeling plasticity across different time scales: the TagTriC model Claudia Clopath ${ }^{1}$, Lorric Ziegler ${ }^{1}$, Lars Buesing ${ }^{1,2}$, Eleni Vasilaki ${ }^{1}$ and Wulfram Gerstner*1
}

\author{
Address: ${ }^{1}$ Brain and Mind Institute, EPFL, Lausanne, Switzerland and ${ }^{2}$ Institute for Theoretical Computer Science, TU-Graz, Austria \\ Email: Wulfram Gerstner* - wulfram.gerstner@epfl.ch \\ * Corresponding author
}

from Eighteenth Annual Computational Neuroscience Meeting: CNS*2009

Berlin, Germany. 18-23 July 2009

Published: 13 July 2009

BMC Neuroscience 2009, I0(SuppI I):PI92 doi:I0.II86/I47I-2202-I0-SI-PI92

This abstract is available from: http://www.biomedcentral.com/I47I-2202/I0/SI/PI92

(c) 2009 Clopath et al; licensee BioMed Central Ltd.

Changes in synaptic efficacies need to be long lasting in order to serve as a substrate for memory. Experimentally, synaptic plasticity exhibits phases covering: i) the induction of long-term potentiation and depression (LTP/LTD) during the early phase of synaptic plasticity, ii) the setting of synaptic tags, a trigger process for protein synthesis, and iii) a slow transition leading to synaptic consolidation during the late phase of synaptic plasticity. We present a mathematical model that describes these different phases of synaptic plasticity. The model explains a large body of experimental data on synaptic tagging and capture, cross tagging, and the late phases of LTP and LTD. Moreover, the model accounts for the dependence of LTP and LTD induction upon voltage and presynaptic stimulation frequency. The stabilization of potentiated synapses during the transition from early to late LTP occurs by protein synthesis dynamics that is shared by groups of synapses. The functional consequence of this shared process is that previously stabilized patterns of strong or weak synapses onto the same postsynaptic neuron are well protected against later changes induced by LTP/LTD protocols at individual synapses. Moreover, the protein synthesis being triggered by a dopamine signal, we establish a link between this neuromodulator and the reward prediction error of reinforcement learning models. See Figure 1. 

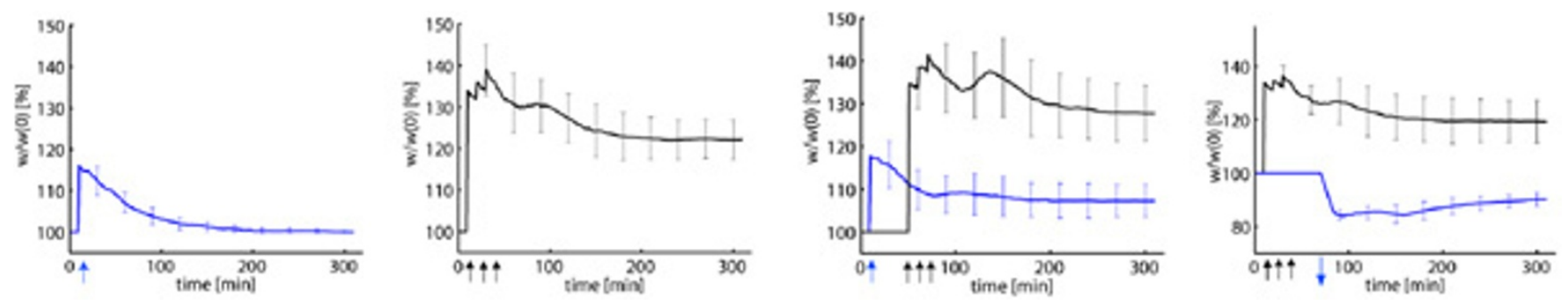

\section{Figure I}

Tagging and cross tagging paradigms. (A) A weak tetanus $(2 \mathrm{I}$ pulses at $100 \mathrm{~Hz})$ applied at a group of 100 synapses at $\mathrm{t}=$ 10 min (arrow) leads to an increased connection weight (blue line) that decays back to baseline. (B) A strong tetanus (I00 pulses at $100 \mathrm{~Hz}$ repeated three times, arrows) leads to late LTP that is sustained for 5 hours (black line). (C) If the weak tetanus (blue arrow) in a first group of synapses is followed thirty minutes later by a strong tetanus (black arrows) in a second group of synapses, the weights in the first group (blue line) and the second group (black line) are stabilized above baseline. (D) Stimulating a group of synapses by a weak low-frequency stimulation (I pulse repeated 900 times at I Hz, blue arrow) 30 minutes after the end of the strong tetanic stimulation of a second group also leads to stabilization of the weights in both groups. Lines indicate the result averaged over 10 repetitions of the simulation experiments and bars standard deviation.

Publish with Bio Med Central and every scientist can read your work free of charge

"BioMed Central will be the most significant development for disseminating the results of biomedical research in our lifetime. "

Sir Paul Nurse, Cancer Research UK

Your research papers will be:

- available free of charge to the entire biomedical community

- peer reviewed and published immediately upon acceptance

- cited in PubMed and archived on PubMed Central

- yours - you keep the copyright 